\title{
NEOCONSERVADORISMO E EDUCAÇÃO BRASILEIRA
}

\author{
Neoconservationsm and brazilian education
}

\author{
Neoconservadorismo y educación brasileña
}

\author{
Daniela Oliveira Vidal da Silva ${ }^{1}$ \\ Vera Lúcia Fernandes de Brito $^{2}$ \\ Cláudio Pinto Nunes ${ }^{3}$
}

\begin{abstract}
Resumo
Neste texto, buscou-se estabelecer uma reflexão sobre pensamento neoconservador e suas influencias e/ou consequências para a educação brasileira, tomando como ponto de referencia para tal incursão, a contextualização histórica do pensamento conversador moderno ao redor do mundo e sua inserção no Território Nacional. Quanto às implicações deste contexto neoconservador para o cenário educacional no país, adotou-se como marco temporal o período pós Impeachement de 2016, representado por algumas das muitas manifestações que expressam a presença de ações antidemocráticas e a aprovação de políticas educacionais baseadas em uma agenda de contrarreformas. Tais expressões podem ser identificadas no movimento denominado Escola sem Partido (ESP), na Reforma do Ensino Médio, na aprovação da Base Nacional Comum Curricular (BNCC) e no crescimento das propostas do Projeto de militarização das escolas públicas. Pode-se concluir que o neoconservadorismo representa e se constitui como uma ameaça à escolarização pública e democrática da nação brasileira.
\end{abstract}

PALAVRAS-CHAVE: Neoconservadorismo. Antidemocrática. Educação Brasileira.

\begin{abstract}
In this text, we sought to establish a reflection on neoconservative thinking and its influences and/or consequences for Brazilian education, taking as a point of reference for such an
\end{abstract}

\footnotetext{
${ }^{1}$ Mestre em Educação pelo Programa de Pós-Graduação em Educação - PPGED UESB. Membro do Grupo de Pesquisa Didática, Formação e Trabalho Docente (Difort/UESB/CNPq). Assessora Pedagógica do Centro Universitário UniFTC, campus Vitória da Conquista - Bahia. E-mail: danielaovdasilva@gmail.com Orcid: http://orcid.org/0000-0002-2316-3035

${ }^{2}$ Mestre em Educação pelo Programa de Pós-Graduação em Educação- PPGED UESB. Pedagoga do Instituto Federal de Educação, Ciência e Tecnologia Baiano Campus Itapetinga. Membro do Grupo de Pesquisa Didática, Formação e Trabalho Docente (Difort/CNPq). Endereço profissional: Instituto Federal de Educação, Ciência e Tecnologia Baiano, Km 02 Clerolandia 45700000 - Itapetinga, BA/Brasil. Email: vlfbrito@gmail.com Orcid: http://orcid.org/0000-0003-0857-0174

${ }^{3}$ Doutor em Educação pela Universidade Federal do Rio Grande do Norte (UFRN), Pós-Doutor em Educação pela Universidade Federal de Minas Gerais (UFMG). Professor da Universidade Estadual do Sudoeste da Bahia (UESB), coordenador do Programa de Pós-Graduação em Educação (PPGED/UESB). Vice-Presidente Nordeste da Associação Nacional de Pesquisa e Pós-Graduação em Educação (ANPEd). Líder do Grupo de Estudos Didática, Formação e Trabalho Docente (Difort/CNPq). Endereço profissional: Universidade Estadual do Sudoeste da Bahia, Departamento de Filosofia e Ciências Humanas, Vitória da Conquista, Estrada do Bem-Querer, Km 04 Candeias 45083900 - Vitória da Conquista, BA/Brasil. Contato profissional: (77) 3424-8652. E-mail: claudionunesba@ hotmail.com Orcid: http://orcid.org/0000-0003-1514-6961
} 
ISSN

incursion, the historical contextualization of modern conversational thinking around the world and its insertion in the National Territory. As for the implications of this neoconservative context for the educational scenario in the country, the post-Impeachment period of 2016 was adopted as a time frame, represented by some of the many manifestations that express the presence of anti-democratic actions and the approval of educational policies based on a counterreform agenda. Such expressions can be identified in the movement called School Without Party (ESP), in the Reform of Secondary Education, in the approval of the National Common Curricular Base (BNCC) and in the growth of the proposals of the Project of militarization of public schools. It can be concluded that neoconservationsm represents and constitutes a threat to the public and democratic schooling of the Brazilian nation.

KEYWORDS: Neoconservationsm. Anti-democratic. Brazilian Education.

\section{Resumen}

En este texto, buscamos establecer una reflexión sobre el pensamiento neoconservador y sus influencias y/o consecuencias para la educación brasileña, tomando como punto de referencia para tal incursión, la contextualización histórica del pensamiento conversacional moderno alrededor del mundo y su inserción en el territorio nacional. En cuanto a las implicaciones de este contexto neoconservador para el escenario educativo en el país, el período posterior a la Impeachement de 2016 se adoptó como un marco de tiempo, representado por algunas de las muchas manifestaciones que expresan la presencia de acciones antidemocráticas y la aprobación de políticas educativas basadas en una agenda de contrarreforma. Dichas expresiones pueden identificarse en el movimiento llamado Escuela Sin Partido (ESP), en la Reforma de la Escuela Secundaria, en la aprobación de la Base Nacional Curricular Común (BNCC) y en el crecimiento de las propuestas del proyecto de militarización de las escuelas públicas. Se puede concluir que el neoconservadurismo representa y constituye una amenaza para la educación pública y democrática de la nación brasileña.

PALABRAS CLAVE: Neoconservadorismo. Antidemocrático. Educación brasileña.

\section{INTRODUÇÃO}

O Brasil tem vivenciado nos últimos anos, em especial, a partir do ano de 2016, um período marcado pela intensificação do autoritarismo, com características antidemocráticas, baseadas em uma agenda de contrarreformas, causando um profundo retrocesso para os diferentes setores da vida contemporânea, sobretudo para a dimensão social. Na prática, esse contexto se materializa através do desmonte de direitos trabalhistas adquiridos e do congelamento em investimentos públicos, acrescidos ainda por um recrudescimento do pensamento conservador baseado na defesa da família tradicional e em princípios religiosos. Essa complexa conjuntura aproxima o Brasil de um fenômeno denominado Neoconservadorismo.

Destarte, partindo de tal premissa, este texto busca estabelecer uma reflexão sobre o modo como este fenômeno neoconservador se constitui e como ele representa uma ameaça à escolarização pública e democrática da nação brasileira.

Numa tentativa de se constituir uma conexão entre o movimento neoconversadorista e seus desdobramentos na política nacional, especialmente no pós Impeachement de 2016, tratar-se-á de apresentar num primeiro momento a contextualização histórica do conservadorismo moderno ao redor do mundo e sua inserção no Território Nacional. Posteriormente, serão discutidas as consequências deste processo no cenário educacional do Brasil. Para tal análise serão abordadas as seguintes 
ISSN

pautas: o Movimento Escola sem partido, a Reforma do Ensino Médio, a Base Nacional Comum Curricular e o Projeto Escola Cívico- Militar.

Para alcançar o objetivo proposto neste trabalho, apropriou-se do suporte dos estudos de autores que retratam o tema, a exemplo de Apple (2000), Barroco (2015), Biroli (2018), Lima e Hypolito (2019), Lacerda (2019), Miguel (2016), Moll (2010), Penna (2015, 2018, 2019), Souza (2016), Brito, Prado e Nunes (2017), Castro Neta, Cardoso e Nunes (2018), Silva, Brito e Nunes (2019), entre outros.

Valeu-se também da apreciação de regulamentações brasileiras que legislam sobre a educação nacional, aprovadas a partir do ano de 2016, assim como em Projetos de Lei em tramitação, tais como: Lei $\mathrm{n}^{\circ}$ 13.415/2017 (BRASIL, 2017), que altera as Leis $\mathrm{n}^{\circ}$ 9.394, de 20 de dezembro de 1996, que estabelece as diretrizes e bases da educação nacional; Resolução no 4/2018 (BRASIL, 2018), que institui a Base Nacional Comum Curricular na Etapa do Ensino Médio (BNCC-EM), como etapa final da Educação Básica, nos termos do artigo 35 da LDB, completando o conjunto constituído pela BNCC da Educação Infantil e do Ensino Fundamental, com base na Resolução CNE/CP n ${ }^{\circ}$ 2/2017, fundamentada no Parecer CNE/CP n ${ }^{\circ}$ 15/2017; Decreto $n^{\circ} 10.004 /$ 2019 (BRASIL, 2019), que institui o Programa Nacional das Escolas Cívico-Militares; Portaria $n^{\circ}$ 2.015/2019 (Brasil 2019), que regulamenta a implantação do Programa Nacional das Escolas Cívico-Militares - Pecim em 2020, para consolidar o modelo de Escola Cívico-Militar - Ecim nos estados, nos municípios e no Distrito Federal.Empreendeu-se também para subsidiar a escrita deste, à análise do Projeto de Lei 246/2019, que institui o "Programa Escola sem Partido".

\section{Contextualização Histórica do Pensamento Conservador Moderno}

Visando estabelecer um percurso histórico de referência para delimitar o período de análise do movimento neoconservador no Brasil, neste texto, destaca-se como marco inicial o ano de 2014, inserindo neste processo a crise econômica e o desfecho das eleições presidenciais deste ano.

Uma vez que as circunstâncias que envolvem os princípios políticos e econômicos de um país não se dão de modo isolado, antes de adentrar numa análise do conjunto de fatores que desencadeou a conjuntura atual da política nacional brasileira, faz-se necessária uma rápida contextualização da trajetória histórica do pensamento conservadorista moderno em âmbito internacional.

Deste modo, a retrospectiva iniciar-se-á por uma rápida passagem no século XVIII, apresentando Edmund Burke, que é considerado o pai do conservadorismo clássico e sua Obra "Reflexões Sobre a Revolução em França", publicada no ano de 1790, a qual é classificada como o ponto de partida deste pensamento social e político. Nela, Burke faz críticas à Revolução Francesa, defendendo a manutenção da ordem tradicional, indo de encontro aos ideais defendidos pelos revolucionários franceses. Conforme descrito por Souza (2016, p. 115), "para Burke, a revolução insurrecional, jacobina, é tomada, de maneira unilateral, como momento de decadência e degradação, no qual a ordem estabelecida é destruída e as tradições, rebaixadas".

Em termos políticos o movimento conservadorista daquele período se materializava com o surgimento de partidos políticos que tinham por objetivo a manutenção dos poderes e das instituições após a queda do antigo regime, denominado de Absolutismo, em países como Portugal, Espanha, Inglaterra e França. 
ISSN

Exemplificando este contexto, destacam-se os partidos Tory na Inglaterra e o partido da Restauração na França.

Dando um salto no tempo, passando neste ponto, das origens do movimento conservador clássico da Europa, do século XVIII, para o pensamento neoconservador do século XX, faz-se necessário antes de adentrar no debate sobre a atual versão do conservadorismo contemporâneo, partir da década de 1960, uma rápida contextualização de alguns acontecimentos nos Estados Unidos, situados no período de 1930 a 1940.

Os primeiros pensamentos que culminaram posteriormente na nova denominação para conservadorismo clássico, o neoconservarismo ou pensamento neoconservador, têm suas raízes identificadas no período de 1930 a 1940, com um grupo de pensadores que ficaram conhecidos como "Intelectuais de Nova Yorque". Para Finguerut (2008, p. 18) "A trajetória do pensamento neoconservador começa nos anos de 1930 com a chegada dos refugiados europeus, principalmente alemães, a Nova York entre 1933 e 1939".

Apesar da grande maioria destes intelectuais terem feito parte do universo do socialismo na Europa, alguns comungavam de ideais conservadores, ligados às questões da manutenção da ordem e do funcionamento da sociedade. Por tal motivo, este grupo começou a ser criticado pela esquerda americana e assim se aproximaram de grupos conservadores. A partir deste grupo de intelectuais são publicadas duas revistas; em 1945, a obra intitulada "Commentary" e em 1960 a "The PublicInterest", ambas consideradas como fundadoras do pensamento neoconservadorista.

Estudos (SANTOS, 2016) apontam que o conservadorismo clássico recebeu a denominação intitulada neoconservadorismo entre as décadas de 1960 e 1970, nos Estados Unidos. O termo "neoconservador" foi utilizado pela primeira, de modo pejorativo, por membros por partido Democrata para denominaram ex-colegas que tinham migrado para o partido Republicano.

Assim como Edmund Burke é considerado o pai do conservadorismo clássico, temos no pensamento neoconservador norte-americano dos anos de 1960, a referência de Irving Kristol, citado por muitos neoconservadores ou até por estudiosos contrários a tal pensamento, como sendo Kristol, o "padrinho do neoconservadorismo", conforme relata Teixeira (2010, p. 12), do período datado a partir de 1960.

Segundo Finguerut (2008),

\footnotetext{
Mais do que dar fama aos neoconservadores, Kristol mostrou que a definição do pensamento neoconservador não se faz no âmbito doméstico dos EUA, mas na política externa. Não se trata de buscar novos adeptos, antes, de superar o pensamento conservador marcado, na política externa, pelo realismo e pela promoção de valores americanos, reinterpretando o internacionalismo de Woodrow Wilson e produzindo uma postura internacional capaz de fundir o poder americano com os princípios americanos. (FINGUERUT, 2008, p. 19).
}

Os ideais neoconservadores defendiam a tese de um Estado forte, entretanto, com menos impostos, assim como não eram adeptos do pensamento conservador clássico. Em relação à política externa, defendiam o patriotismo como algo natural, 
saudável e próprio os Estados Unidos; pregava a oposição aos governos mundiais, o que desencadeou a "tirania generalizada"; interesses ideológicos e revalorização dos interesses nacionais (FINGUERUT, 2008).

O neoconservadorismo nos Estados Unidos tem na sua formação de origem grupos de extrema direita, conforme pode ser constato em Lacerda (2019, p. 35) o qual define que este movimento "é um ideário conservador e de direita, e sua peculiaridade reside na centralidade que atribui às questões relativas à família, à sexualidade e à reprodução e aos valores cristãos."

Apesar do ideário deste novo modelo de conservadorismo ser identificado já na década de 1930, é somente a partir dos anos de 1980, com a chegada de Ronald Reagan ao poder nos Estados Unidos que o pensamento neoconservador ganhou destaque. A nova direita se transformou na nova força política norte americana a partir das eleições para Casa Branca de 1980 e a ala neoconservadorista do partido republicano seu maior representante. Dentre alguns projetos deste modelo de política, destacava-se a redução de programas de Bem Estar Social como solução econômica para a crise de desemprego de trabalhares poucos especializados. Outro ponto de destaque nesta etapa de consolidação deste novo modelo de ideário conservadorista é a questão do fundamentalismo religioso da nova direita religiosa.

É possível identificar no trabalho de Souza (2016) que o ponto central em comum desde conservadores clássicos, até os neoconservadores da atualidade é a negação de qualquer movimento que represente a mudança, a alteração da ordem vigente, ainda que não chegue a ser uma revolução. $O$ pensamento neoconservador continua defendendo a manutenção da hegemonia conservadora. Segundo Souza (2016),

\begin{abstract}
A imagem da revolução como processo substanciado pelo fanatismo laico e dogmático, inimigo da pacífica continuidade e das mudanças ocasionais da sociedade, presente no discurso conservador atual, tem sua origem nas Reflexões. Os defensores dessa corrente, na contemporaneidade, procuram, tal como Burke, acusar aqueles que lutam por avanços civilizatórios de serem "inimigos da sociedade", de suas instituições e tradições 74 - algo típico das ideologias conservadoras de uma maneira geral. (SOUZA, 2016, p. 116).
\end{abstract}

Passando agora da década de 1980 e da Era Conservadorista de Reagan para o Neoconservadorismo internacional do século XXI, dentre vários exemplos que poderiam ser apresentados neste estudo, selecionaram-se, como referência do pensamento conservador atual, os acontecimentos e desdobramentos das eleições de Donald Trump, nos Estados Unidos, no ano de 2016.

Poder-se-ia apresentar aqui várias representações internacionais para contextualizar o pensamento conservadorista na atualidade, contudo, a escolha pelos Estados Unidos, deu-se pela forte influência que o Presidente Trump demonstra representar para o atual presidente do Brasil, Jair Bolsonaro. Entretanto, apesar da opção por Donald Trump para introduzir o neo conservadorismo no Brasil, faz necessário destacar que esta tendência política sofreu desde a sua candidatura e ainda hoje sobre críticas do partido político Republicano norte americano que representa o pensamento neoconservadorista desde a década de 1960. As críticas dos neoconservadores se referem principalmente à posição de Trump quanto ao seu discurso 
ISSN

para a política externa, a qual é caracterizada por muitos de analistas como sendo uma "posição isolacionista", o que coloca em risco o liberalismo internacional.

Contudo, apesar de não contar com o apoio de muitos republicanos, Trump conseguiu ser eleito presidente dos Estados Unidos, tendo como frente principal de sua campanha a criminalização das instituições políticas tradicionais dos Estados Unidos e o sentimento de descontentamento dos norte americano com o sistema político do país e o combate à corrupção. Nesse sentido, o governo de Trump chega ao poder como representação do pensamento de nova direita, que vai de encontro aos ideais originais do neoconservadorismo contemporâneo, mas que resgata pensamento conservador e o alia a interesses econômicos vinculados ao neoliberalismo, como bem definem Lima e Hypolito (2019, p. 7) a modernização conservadora "que articula tradições culturais conservadoras a interesses econômicos neoliberais e interesses religiosos conservadores, para impor a agenda neoliberal e neoconservadora na educação e nas definições do papel do Estado".

Tendo em vista que os processos econômicos e políticos de um país estão inter relacionados com o contexto mundial, fez-se necessária uma breve retrospectiva do pensamento conservador moderno, com intuito de melhor compreender a aproximação entre o conservadorismo e o neoliberalismo no cenário brasileiro a partir de 2014, até os dias atuais. Para Barroco (2015, p. 624), o "conservadorismo se reatualizou, incorporando princípios econômicos do neoliberalismo, sem abrir mão do seu ideário e do seu modo específico de compreender a realidade".

As eleições de 2014, que reelegeu Dilma Rousseff para seu segundo mandato de presidenta do Brasil, é marcada também pela vitória de representantes do Congresso Nacional da ala mais conversadora no país desde o período da redemocratização nacional, demarcando a volta da direita, intitulada por muitos, como a nova direita do Brasil.

O início do segundo mandato de Dilma Rouseff foi marcado por uma série de situações que se caracteriza por boicotes ao Governo, sobretudo por parte de parlamentares (deputados federais e senadores) que formavam um grupo político forte que formavam um grupo político alinhado ao candidato derrotado nas eleições presidenciais, Aécio Neves, os quais se articularam na composição da oposição ao mandato da presidenta eleita. Esse grupo era composto por parlamentares dos partidos de oposição ao governo, inicialmente representados pelos membros do Partido da Social Democracia Brasileira (PSDB), do Democratas (DEM) e parte de representantes no Congresso do Movimento Democrático Brasileiro(MDB - antigo PMDB).

Esse processo que tentava impedir as ações do governo da presidenta Dilma, é retratado por Oliveira (2016), conforme observa a seguir:

Após a proclamação do resultado presidencial de 2014, teve início uma disputa insana que visava impedir a posse e a governabilidade do segundo mandato de Dilma Rousseff, que teria de lidar com uma nova legislatura parlamentar de perfil ainda mais retrógrado e fisiológico do que de costume. Imediatamente, o derrotado Aécio Neves passou a capitanear uma campanha que muito se assemelhava aos dizeres de Carlos Lacerda em relação a Getúlio Vargas: "Não pode se candidatar; se for candidato, não pode ser eleito; se eleito, não pode tomar posse; se tomar posse, não pode governar". (OLIVEIRA, 2016, p. 214) 
Os membros do Congresso Nacional eleitos em 2014 representavam um grupo de parlamentares da ala conservadora do cenário político brasileiro, que ficou conhecido no cenário nacional como a bancada "BBB", conforme retrata Menezes (2017, p.11) fazendo referência às "(letras iniciais do "boi" ligado ao "agrobusiness", da "bala" pertencente às facções de policiais com ares truculentos e, a mais conservadora de todas, a da "bíblia", a maior e ligada à crescente ampliação dos tentáculos das igrejas neopentecostais na política nacional)".

A oposição política, conduzida por representantes dos partidos de oposição, não apenas bloqueou pautas e votações, travando a agenda governista, como também agiu como porta-voz do capital internacional no Congresso Nacional.

E é neste cenário complexo da conjuntura político-econômica brasileira que se configura, no ano de 2016, o processo de impeachment contra a presidenta Dilma Rousseff, legitimamente eleita em 2014. Processo esse definido por alguns autores (SAVIANI, 2017; CASTRO NETA; CARDOSO; NUNES, 2018; SILVA; BRITO; NUNES, 2019) como golpe parlamentar, jurídico (ou constitucional) e midiático. No pós Impeachement de 2016 o vice-presidente Michel Temer assume a presidência da república e adota uma série de reformas, que traz prejuízos e retrocessos para o país, conforme pode ser observado em Brito (2019) a qual destaca que:

\begin{abstract}
Desde que Michel Temer assumiu a presidência da república, uma série de reformas político-econômicas foram adotadas e o Brasil passa a ser governado por uma agenda neoliberal, privatista e excludente, com prejuízos e retrocessos para o Estado de bem-estar social, que atingiram diretamente as políticas sociais, especialmente área da saúde, previdência social e educação. (BRITO, 2019, p.62)
\end{abstract}

As medidas adotadas pelo governo Temer demonstraram as propostas da agenda neoconservadora, vinculada às concepções neoliberais. O corte de recursos e revogação de direitos adquiridos passa a ser a marca principal do seu governo. $\mathrm{Na}$ área educacional, vários projetos foram aprovados, trazendo prejuízo no que vinha sendo realizado, entre os quais se destacam: a Reforma do Ensino Médio, a aprovação Base Nacional Comum Curricular (BNCC), crescimento do movimento Escola sem Partido e a "Emenda Constitucional n. 95/2016, que determina um novo regime fiscal, congelando os gastos do Governo Federal com despesas primárias durante os próximos 20 anos e possibilidade de revisão restrita ao índice de correção por 10 anos" (BRITO, 2019, 63).

Encontra-se também em Santos (2019) respaldo teórico em relação às medidas conservadoras e de cunho neoliberal implementadas pelo governo não eleito de Michel, abaixo:

Com o afastamento de Dilma Rousseff, o vice Michel Temer (PMDB) assumiu a presidência, período que ficou marcado principalmente pela implementação de medidas neoliberais, mas também pelo conservadorismo. Quando assumiu a presidência, Temer formou um governo de homens brancos, e indicou para a Secretaria Nacional de Políticas para as Mulheres Fátima Pelaes, que havia sido deputada federal entre 1991 e 2015 e era 
presidenta do PMDB Mulher. Pelaes ganhou destaque na mídia durante seu mandato como secretária por estar realizando cultos evangélicos na sede da secretaria em Brasília. (SANTOS, 2019, p. 8).

Fazendo um paralelo entre as eleições de 2014 que elegeram um congresso com maioria de deputados que compõem um coletivo de parlamentares atuantes no Congresso Nacional do Brasil, popularmente conhecida como "Bancada BBB"- termo utilizado para referir-se conjuntamente à bancada armamentista ("da bala"), bancada ruralista ("do boi") e à bancada evangélica ("da bíblia"), cujas agendas eram demarcadas por pautas alinhadas à direita política e ao conservadorismo brasileiros.

Entre os acontecimentos que desencadearam o processo de Impeachement de 2016 contra a presidenta Dilma e o governo do presidente Michel Temer, verificaram no Brasil traços expressivos dessa recente corrente neoconservadorismo país, que assume uma nova versão, incorporando características do velho conservadorismo, aliado aos ideais do neoliberalismo.

Segundo Ribeiro, Silva, Cardoso, Nunes (2018), nesta conjuntura é perceptível o domínio do capital e este possui três elementos importantes em sua estrutura, a saber: o estado burguês, a família burguesa e a iniciativa privada. São esses elementos que se unem com o único propósito de obter lucro e explorar o proletariado. Podemos incluir o Estado nos elementos do capitalismo, assim, percebemos que ele trabalha para proteger os interesses da burguesia, o que pode ser comprovado pelo crescimento da iniciativa privada que tem o Estado como grande promotor.

Por fim, chega-se às eleições de 2018 e à vitória de Jair Bolsonaro para Presidência da República do Brasil, um candidato de extrema direita, conforme se verificava nos discursos realizados nas agendas de campanha eleitoral e demais pronunciamentos públicos veiculados pela impressa nacional e internacional. Processo eleitoral este marcado por um pensamento conservadorista, com base num discurso preconceituoso em relação aos negros, índios, homossexuais e às mulheres. E a partir daí, o que se pode perceber desde o início seu mandato, em janeiro de 2019, é que o atual governo do Brasil vem se consolidando através de medidas antidemocráticas, por meio de ataques aos direitos dos trabalhadores e a qualquer discurso que defenda as questões de gênero, sexualidade, entre outros.

\section{Expressões neoconservadoras na educação brasileira}

Nunca é demasiado lembrar que as manifestações neoconservadoras que impactaram a educação brasileira ocorreram no já explicitado conturbado contexto político do Golpe parlamentar de 2016, que retira a então Presidenta da República Dilma Rousseff e que assume o vice-presidente Michel Temer, representante explícito da burguesia brasileira e que viria a colocar os planos políticos neoconservadores em rápida execução.

Então, considerando este contexto e suas repercussões na educação brasileira, temos manifestações expressas no movimento denominado Escola sem Partido (ESP), na Reforma do Ensino Médio, na aprovação da Base Nacional Comum Curricular (BNCC) e no crescimento das propostas do Projeto de militarização das escolas públicas. 
O movimento Escola sem Partido vem ganhando visibilidade desde 2004, tendo como fundador e líder o advogado Miguel Nagib. O projeto idealizado por ele deu origem aos Projetos de Lei que se espalharam pelo país e ganharam visibilidade, principalmente, através das redes sociais e o site do movimento 4 . Conforme consta no Projeto original e no site oficial, o objetivo principal do movimento é apresentar um conjunto de medidas para inibir a prática da doutrinação política e ideológica em sala de aula e a tentativa de retirar dos pais dos alunos o direito à educação moral dos seus filhos, proibindo assim a discussão sobre pluralidade cultural.

Segundo Paulino (2018), Em 2014, o ESP ganhou força porque,

[...] foram apresentados dois projetos de lei representando as ideias do ESP, pré-elaborados pelo próprio Miguel Nagib, e adaptados por políticos, sendo o primeiro no Estado do Rio de Janeiro, pelo deputado Flávio Bolsonaro, e, o segundo, no Município do Rio de Janeiro, pelo vereador Carlos Bolsonaro ambos filhos do deputado federal Jair Bolsonaro. A partir daí o modelo de projeto de lei foi disponibilizado no site do ESP, tendo sido tomado por diversos políticos como referência para elaborar novos projetos de lei. (PAULINO, 2018, p. 4)

No Brasil, este movimento é fortemente apoiado por membros de organizações de viés conservador, a exemplo do Movimento Contra Corrupção, liderado pelo ex-ator Alexandre Frota, e o Movimento Brasil Livre (MBL), tendo como um de seus principais representantes o então vereador Fernando Holiday (DEM-SP). Esse vereador, norteado com as ideias do ESP, realizou visitas em algumas escolas públicas de São Paulo com o intuito de fiscalizar as aulas de professores e verificar a prática de doutrinação. A prática de fiscalizar, denunciar e punir os docentes está representada no Projeto de Lei e respaldada no pensamento dos simpatizantes ao movimento, visto que estes estão vinculados a igrejas e partidos políticos conservadores que buscam a não intervenção da escola na educação moral e religiosa dos alunos e que a escola seja um espaço de manutenção de ideias respaldadas nos princípios de manutenção de um status quo e de um ethus consolidados.

O projeto Escola Sem Partido, em seu site oficial na internet, propõe tornar obrigatório em todas as salas de aula do ensino fundamental e médio a fixação de um cartaz com os seguintes dizeres:

1- O professor não se aproveitará da audiência cativa dos alunos para promover os seus próprios interesses, opiniões, concepções ou preferências ideológicas, religiosas, morais, políticas e partidárias;

2- O professor não favorecerá nem prejudicará os alunos em razão de suas convicções políticas, ideológicas, morais ou religiosas, ou da falta delas;

3- O professor não fará propaganda político-partidária em sala de aula, nem incitará seus alunos a participar de manifestações, atos públicos e passeatas;

4- Ao tratar de questões políticas, socioculturais e econômicas, o professor apresentará aos alunos de forma justa - isto é, com a mesma profundidade e seriedade -, as principais versões, teorias, opiniões e perspectivas concorrentes a respeito;

${ }^{4}$ https://www.escolasempartido.org/ 
5- O professor respeitará o direito dos pais a que seus filhos recebam a educação moral que esteja de acordo com suas próprias convicções; 6- O professor não permitirá que os direitos assegurados nos itens anteriores sejam violados pela ação de terceiros, dentro de sala de aula ${ }^{5}$.

Segundo Moura (2016), 62 projetos de lei inspirados no anteprojeto do ESP já foram apresentados, desde o ano de 2014, e tramitaram ou tramitam no Congresso Nacional e nas casas legislativas de pelo menos 12 estados e 23 cidades do Brasil. Nesse âmbito houve também a iniciativa de que este Projeto modificasse a Lei de Diretrizes e Bases da Educação Nacional, a LDBEN.

Para Penna (2017), o discurso produzido pelo Escola sem Partido ganhou força no país porque não se criou resistência, nem combate às ideias

[...] desde o momento em que ele surgiu, em 2004, justamente por parecer absurdo e sem fundamentos legais para aqueles que conhecem o debate educacional, e também porque ele se espalha com muita força, não em debates acadêmicos, mas nas redes sociais. Esse discurso utiliza-se de uma linguagem próxima a do senso comum, recorrendo a dicotomias simplistas que reduzem questões complexas a falsas alternativas e valendo-se de polarizações já existentes no campo político para introduzi-las e reforça-las no campo educacional. Os memes, imagens acompanhadas de breves dizeres, tem uma grande importância nesse discurso simplista. (PENNA, 2017, p.35)

Destartes discussões sobre o Movimento Escola Sem Partido vem sendo destaque nas pesquisas científicas e se tornado preocupação dos estudiosos de políticas públicas educacionais. Em 2020, após diversas tentativas dos apoiadores do ESP em alterar a LDB e abranger a inserção de suas ideias neoconservadoras em mais escolas pelo país, o Supremo Tribunal Federal declarou, por unanimidade, a inconstitucionalidade da lei que veta a discussão de gênero nas escolas de Goiânia, impedindo, assim, que as propostas cresçam pelo país.

Seguindo a onda neoconservadora no Brasil, tivemos em 2016 o Impeachement da então Presidenta Dilma Rousseff. Segundo Silva, Brito e Nunes (2019), foi

\begin{abstract}
Após o golpe de 2016 muitas medidas foram lançadas contra a educação pública brasileira, a exemplo do corte de verbas para a Educação Superior, da Reforma do Ensino Médio, que sem nenhum debate com professores, estudantes e a sociedade, modificou toda a estrutura do ensino médio no país, do crescimento do movimento Escola sem Partido, da Emenda Constitucional (EC) n. ${ }^{\circ}$ 95/2016, que altera o Ato das Disposições Constitucionais Transitórias, para instituir o Novo Regime Fiscal, e dá outras providências (BRASIL, 2016) e afeta diretamente o cumprimento das metas do Plano Nacional de Educação, e a Reforma da Previdência que retira direitos dos profissionais da educação. Todas essas ações do governo de Temer representam um ataque direto à educação, através de políticas que conduzem à precarização e à privatização da educação pública no país. (SILVA; BRITO; NUNES, 2019, p. 412-413)
\end{abstract}

\footnotetext{
${ }^{5}$ Site do ESP: Http://www.programaescolasempartido.org/acesso em 21.04.2020
} 
Foi neste contexto e sob a presidência do Michel Temer, que a Reforma do Ensino Médio, é aprovada de forma autoritária pela Lei 13.415 de 16 de fevereiro de 2017. Esta Lei modifica toda a estrutura do ensino médio no Brasil, segmentando as disciplinas de acordo com áreas do conhecimento e implementa o ensino integral neste segmento da educação básica.

A implantação desta reforma está atrelada à Base Nacional Comum Curricular (BNCC), que compõe um conjunto de orientações norteadoras para os currículos. O debate sobre a implementação de um currículo básico comum, não é recente na educação brasileira. Vem desde a Constituição Federal de 1988, porém não explicitando que esta base seria de conhecimentos nacionais, mas que garantisse o "respeito aos valores culturais e artísticos, nacionais e regionais" (CF, 1988, art. 210). Este debate é intensificado a partir da Lei de Diretrizes e Bases da Educação Nacional de 1996, que assegura para a Educação Básica que

Os currículos do ensino fundamental e médio devem ter uma base nacional comum, a ser complementada, em cada sistema de ensino e estabelecimento escolar, por uma parte diversificada, exigida pelas características regionais e locais da sociedade, da cultura, da economia e da clientela. (LDBEN, 1996, art. 26).

Após a LDB, outros documentos seguiram apresentando a necessidade de uma base nacional comum. Segundo Gonçalvez; Machado; Correia (2020),

\begin{abstract}
De 1997, com a elaboração dos PCNs, até 2014, com a $2^{\text {a }}$ Conferência Nacional pela Educação (Conae), temos um longo processo de organização da educação nacional, que inclui o Programa Currículo em Movimento (2008 a 2010), as Diretrizes Curriculares Nacionais Gerais para a Educação Básica (DCNs), Pacto Nacional pela Alfabetização na Idade Certa (PNAIC, 2012), Pacto Nacional de Fortalecimento do Ensino Médio (PNFEM, 2013), a regulamentação do Plano Nacional de Educação (PNE, 2014). (GONÇALVEZ; MACHADO; CORREIA, 2020, p. 341).
\end{abstract}

Desta forma é possível perceber que a discussão está presente há muito nas políticas educacionais brasileiras. Não nos determos a apresentar o percurso da discussão da Base Nacional Comum Curricular desde a sua primeira versão. O que nos vale é destacar que foi no desgoverno de Michel Temer que este documento foi aprovado num contexto de redução de debates das entidades de classes que representam a educação nacional.

Enfim, fica a Base Nacional Comum Curricular - BNCC da Educação Infantil e Ensino Fundamental aprovada e regulamentada pela Resolução n ${ }^{\circ} 2$ do CNE em 2017 e do Ensino Médio pela Resolução $n^{\circ} 4$ de 2018, instituindo mudanças em um conjunto da legislação educacional e colocando os profissionais da educação numa luta diária para compreender e colocar em prática todas as exigências para um novo formato de planejamentos e aulas, afetando diretamente aqueles atores que estão no cão da escola.

Outra investida presente na atual conjuntura política do Brasil e que também contribui muito para o neoconservadorismo e que, portanto, também se constitui uma ameaça à educação e à democrática do Brasil e uma investida que ganha força a partir dos governos que se estabeleceram após o impeachment de 2016 e tem como intuito 
estabelecer um processo de militariazação das escolas públicas. Trata-se do Programa Nacional das Escolas Cívico-Militares, proposto pelo Ministério da Educação (MEC), com previsão de abrangência em 23 estados e no Distrito Federal, pensado para ser iniciado em 2020, como projeto piloto.

A proposta do MEC é que o programa seja considerado como um "modelo de escola de alto nível" que segue "padrões de ensino e modelos pedagógicos empregados nos colégios militares do Exército, das Polícias Militares e dos Corpos de Bombeiros Militares" (BRASIL, 2019, p.11). Com isso a intenção do MEC é que, aos poucos, o programa seria ampliado para muitas escolas públicas por todo o país.

$\mathrm{Na}$ centralidade do processo, como estacam Alves e Toschi (2019), a militarização das escolas públicas consiste em transferência da gestão de escolas públicas para a Corporação da Política Militar, com o propósito de estabelecer nas escolas uma disciplina no estilo militar. Nesse sentido, o principio norteador do programa se baseia na ideia de que a ordem gera o progresso e, nessa perspectiva, a ordem no ambiente escolar de estabeleceria por via da transposição do modelo de disciplina observada nos espaços militares para as escolas públicas.

\section{CONSIDERAÇÕES FINAIS}

O objetivo principal deste texto foi estabelecer uma reflexão sobre o modo como o fenômeno neoconservador se constitui e como ele representa uma ameaça à escolarização pública e democrática da nação brasileira. Para tanto, foi necessário contextualizar o aspectos políticos deste fenômeno e suas influências na economia, na política e na educação.

É notório que atualmente os efeitos do neo(conservadorismo) podem ser sentidos de forma global e, no Brasil, as inter-relações com a política e os grupos religiosos representados no parlamento, influenciam e atacam a educação pública, as políticas educacionais, a autonomia docente e o currículo escolar, causando transtornos sociais e culturais.

Faz-se urgente que a temática seja aprofundada e debatida para que possamos avançar em independência de pensamento e fundamentos da educação, do currículo escolar inclusivo, da diversidade cultural, religiosa e de gênero e que os conceitos defendidos possam ser fundamentados para que a escolarização pública, laica, inclusiva e democrática se cumpra.

\section{REFERÊNCIAS}

ALVES, Miriam Fábia; TOSCHI, Mirza Seabra. A militarização das escolas públicas: uma análise a partir das pesquisas da área de educação no Brasil. Revista Brasileira de Política e Administração da Educação, v. 35, n. 3, 2019. Disponível em: https://seer.ufrgs.br/rbpae/article/view/96283. Acesso em 28 de março de 2020.

APPLE, Michael W. Política cultural e educação. Tradução de José do Amaral Ferreira. São Paulo: Cortez, 2000. 
ISSN

BARROCO, Maria Lúcia S. Não passarão! Ofensiva neoconservadora e serviço social. Serviço Social \& Sociedade, São Paulo, n. 124, p. 623-636, out./dez. 2015

BIROLI, F. Reação conservadora, democracia e conhecimento. Revista de Antropologia, São Paulo, v. 61, n. 1, p. 83-94, 2018. DOI: ttps://doi.org/10.11606/21790892.ra.2018.145515

BRASIL. Lei $n^{\circ}$ 9.394, de 20 de dezembro de 1996. Estabelece as diretrizes e bases da educação nacional. Disponível em: 〈http://portal.mec.gov.br/arquivos/pdf/ldb.pdf〉. Acesso em: 05 dez. 2019.

BRASIL. Emenda Constitucional $n^{\circ} 95$ de 15/12/2016. Altera o ato das disposições constitucionais transitórias, para instituir o novo regime fiscal, e dá outras providências. Brasília, Dezembro, 2016. Disponível em:

http://legis.senado.leg.br/legislacao/ListaTextoSigen. action?norma=540698\&id=143747 70\&idBinario $=15655553 \&$ mime $=$ application/rtf.n. Acesso em: 03 agosto de 2018 .

BRASIL. Lei $n^{\circ}$ 13.415/2017, de 13 de fevereiro de 2017, Altera as Leis nos 9.394, de 20 de dezembro de 1996, que estabelece as diretrizes e bases da educação nacional, e 11.494, de 20 de junho 2007, que regulamenta o Fundo de Manutenção e Desenvolvimento da Educação Básica e de Valorização dos Profissionais da Educação, a Consolidação das Leis do Trabalho - CLT, aprovada pelo Decreto-Lei no 5.452, de 10 de maio de 1943, e o Decreto-Lei no 236, de 28 de fevereiro de 1967; revoga a Lei no 11.161, de 5 de agosto de 2005; e institui a Política de Fomento à Implementação de Escolas de Ensino Médio em Tempo Integral. 2017. Disponível em: < http://www.planalto.gov.br/ccivil_03/_ato2015-2018/2017/lei/L13415.htm>. Acesso em: 10 março 2020.

BRASIL. Resolução $n^{o} 2$, de 22 de dezembro de 2017. Institui e orienta a implantação da Base Nacional Comum Curricular, a ser respeitada obrigatoriamente ao longo das etapas e respectivas modalidades no âmbito da Educação Básica. Diário Oficial da União. Seção 1. Brasília, DF, 22 dez. 2017c. Disponível em < http://basenacionalcomum.mec.gov.br/images/historico/RESOLUCAOCNE_CP222DE DEZEMBRODE2017.pdf> Acesso em: 28 dez. 2019

BRASIL. Parecer CNE/CP $n^{\circ} 15$, de 21 de dezembro de 2017. Que trata da Base Nacional Comum Curricular (BNCC). Homologado através da Portaria n. ${ }^{\circ} 1.570$, do Diário Oficial da União. Seção 1. Brasília, DF, 22 dez. 2017c. Disponível em <http://portal.mec.gov.br/docman/dezembro-2017-pdf/78631-pcp015-17-pdf/file.pdf> Acesso em: 28 dez. 2019.

BRASIL. Resolução $n^{o}$ 4, de 17 de dezembro de 2018. Institui a Base Nacional Comum Curricular na Etapa do Ensino Médio (BNCC-EM), como etapa final da Educação Básica, nos termos do artigo 35 da LDB, completando o conjunto constituído pela 
ISSN

BNCC da Educação Infantil e do Ensino Fundamental, com base na Resolução CNE/CP $n^{\circ}$ 2/2017, fundamentada no Parecer CNE/CP nº 15/2017. Diário Oficial da União.

Seção 1. Brasília, DF, 18 dez. 2018. Disponível em

<http://http://www.in.gov.br/materia/-

/asset_publisher/Kujrw0TZC2Mb/content/id/55640296> Acesso em: 10 de jan. 2020

BRASIL. Decreto no 10.004, de 5 de setembro de 2019. Institui o Programa Nacional das Escolas Cívico-Militares. Disponível em: <https://www2.camara. leg.br/legin/fed/decret/2019/decreto-10004-5-setembro-2019-789086publicacaooriginal-159009-pe.html>. Acesso em: 2 nov. 2019.

BRASIL. Portaria . $^{\circ} 2.015$, de 20 de dezembro de 2019. Regulamenta a implantação do Programa Nacional das Escolas Cívico-Militares - Pecim em 2020, para consolidar o modelo de Escola Cívico-Militar - Ecim nos estados, nos municípios e no Distrito Federal. Disponível em: <http://www.in.gov.br/en/web/dou/-/portaria-n-2.015-de-20de-novembro-de-2019-228864271> Acesso em: 2 de abril. 2019.

BRASIL. Projeto de Lei 246/2019. Projeto de Lei que institui o Programa Escola sem Partido. Disponível em: < https://www.camara.leg.br/proposicoesWeb/prop_mostrarintegra;jsessionid=46FD4CE DD38E8F1495BF6F2DB137163D.proposicoesWebExterno1?codteor=1707037\&filena me=Tramitacao-PL+246/2019>. Acesso em: 07 março 2020.

BRASIL. Decreto $n^{\circ}$ 9.465, de 2 de janeiro de 2019. Disponível em: https://www.conjur.com.br/dl/decreto-9465-janeiro-2019-ensino-militar.pdf. Acesso em 29 janeiro de 2020.

BRITO, Vera Lucia Fernandes. Políticas públicas para valorização docente: planos de carreira e remuneração das redes municipais do território de identidade do médio sudoeste da Bahia (TIMSOBA). Dissertação. Programa de Pós-Graduação em educação. Universidade Estadual do Sudoeste da Bahia, 2019, 199p. Disponível em: <http://www2.uesb.br/ppg/ppged/wp-content/uploads/2019/05/VERA-L\%C3\%9ACIAFERNANDES-DE-BRITO.pdf $>$. Acesso em 29 de janeiro de 2020.

BRITO, Regivane dos Santos; PRADO, Jany Rodrigues; NUNES, Claudio Pinto. As condições de trabalho docente e o pós-estado de bem-estar social. Tempos e Espaços em Educação, Aracaju, v. 10, n. 23, 2017. Disponível em: $<$ https://seer.ufs.br/index.php/revtee/article/view/6676>. Acesso em 08 de fevereiro de 2020 .

CASTRO NETA, Abília Ana de; CARDOSO, Berta Leni Costa Cardoso; NUNES, Claudio Pinto. Reformas Educacionais no Contexto Pós-Golpe de 2016. Educação em Debate, Fortaleza, v. 40,, n. 77, 2018. Disponível em: 
ISSN

<http://www.periodicosfaced.ufc.br/index.php/educacaoemdebate/article/view/703/0>. Acesso em 10 de fevereiro de 2020.

FINGUERUT, A. "A influência do pensamento neoconservador na política externa de George W. Bush". 2008. 150f. Dissertação (Mestrado em Sociologia). Universidade Estadual Paulista "Júlio de Mesquita Filho", Araraquara, 2008.Disponível em: <https://http://www.repositorio.unicamp.br/bitstream/REPOSIP/281232/1/Finguerut_Ar iel_D.pdf> Acesso em: 21 de abril 2020.

GOLÇALVES, Rafael Marques; MACHADO, Tânia Mara Rezendo; CORREIA, Maria José Nascimento. A BNCC na contramão das demandas sociais: planejamento com e planejamento para. Revista Práxis Educacional, Vitória da Conquista, Bahia, Brasil, v. 16, n. 38, p. 338-351, jan./mar. 2020. Disponível em: $<$ http://periodicos2.uesb.br/index.php/praxis/article/view/6012/4505>. Acesso em 04 de maio de 2020.

LACERDA, M. B. O novo conservadorismo brasileiro: de Reagan a Bolsonaro. Porto Alegre: Zouk, 2019.

LIMA, I. G..; HYPOLITO, A. M. A expansão do neoconservadorismo na educação brasileira. Educação e Pesquisa, São Paulo, v. 45, p. 1-15, ago. 2019. Disponível em: <http://www.scielo.br/pdf/ep/v45/1517-9702-ep-45-e190901.pdf>. Acesso em: 29 de março 2020.

MENEZES, W. (2017). Estado de exceção e democracia fragmentada no Brasil: um breve ensaio a respeito do "golpeachment" de 2016. Revista Lumen, 2. Disponível em: <https:// http://45.79.222.71/index.php/lumen/article/viewFile/47/78> Acesso em: 18 de fevereiro 2020.

MIGUEL, Luis Felipe. Da "doutrinação marxista" à "ideologia de gênero": Escola sem Partido e as leis da mordaça no parlamento brasileiro. Direito \& Práxis, Rio de Janeiro, v. 7, n. 15, p. 590-621, 2016. Disponível em: <https://www.epublicacoes.uerj.br/index.php/revistaceaju/article/view/25163/18213> Acesso em: 18 de abril 2020.

MOLL, Roberto. Reaganetion: a nação e o nacionalismo (neo)conservador nos Estados Unidos (1981-1988). 2010. 265 f. Dissertação (Mestrado em História) - Programa de Pós-Graduação História, Universidade Federal Fluminense, Niterói, 2010. Disponível em: 〈https://www.historia.uff.br/stricto/td/1381.pdf>. Acesso em: 15 abril 2020.

MOURA, Fernanda. P. de. "Escola Sem Partido”: relações entre Estado, educação e religião e os impactos no ensino de história. 189 f. Dissertação - (Mestrado Profissional 
ISSN

em Ensino de História). Instituto de História, Universidade Federal do Rio de Janeiro, Rio de Janeiro, 2016.

OLIVEIRA, Tiago Bernardon. (2016). O golpe de 2016: breve ensaio de história imediata sobre democracia e autoritarismo. Historiae, 7(2), 191-231. Disponível em: <HTTPShttps://periodicos.furg.br/hist/article/view/6726.> Acesso em: 22 abril 2020.

PAULINO, Carla Viviane. O impulso neoliberal e neoconservador na educação brasileira: a imagem do "professor doutrinador" e o projeto "escola sem partido". RevistaEducere Et Educare. vl. 13, N. 28, maio/ago. 2018. Ahead of Print. DOI: 10.17648/educare.v13i28.18731

PENNA, Fernando. O ódio aos professores. Movimento Liberdade para educar, 2015. Disponível em: <https://liberdadeparaensinar.wordpress.com /2015/09/18/o-odio-aosprofessores/. Acesso em: 21 abr. 2020.

PENNA, F. de A. O discurso reacionário de defesa do projeto "Escola sem Partido". Revista Quaestio, Sorocaba, v. 20, n. 3, p. 567-581, dez. 2018. DOI:

<https://doi.org/10.22483/2177- 5796.2018v20n3p567-581>

PENNA, F. de A. A defesa da "educação domiciliar" através do ataque à educação democrática: a especificidade da escola como espaço de dissenso. Linguagens, Educação e Sociedade, Teresina, n. 42, p. 8-28, maio/ago. 2019. DOI: <https://doi.org/10.26694/les.v0i42.9336>

RIBEIRO, Júlia Cecília de Oliveira Alves; SILVA, Daniela Oliveira Vidal da; CARDOSO, Elisângela Andrade Moreira; NUNES, Cláudio Pinto. A educação do campo em tempos de privatização e golpe. In: Revista Cenas Educacionais, Caetité Bahia - Brasil, v. 1, n. 1, p. 111-128, jan./jun. 2018.

SANTOS, Rayani Mariano dos. Pensando a família como um dos pontos de intersecção entre o neoliberalismo e o conservadorismo. In: III Simpósio Pós-Estruturalismo e Teoria Social, 2019, Pelotas. Disponível em: https <https://wp.ufpel.edu.br/legadolaclau/files/2019/07/ARTIGO-Santos.pdf>. Acesso em 12 de abril de 2020.

SANTOS, Arlete Ramos dos. Aliança (neo)desenvolvimentista e decadência ideológica no campo: movimentos sociais e reforma agrária do consenso. Curitiba: CRV, 2016.

SAVIANNI, D. A crise política no Brasil, o golpe e o papel da educação na resistência e na transformação. In: LUCENA, C.; PREVITALLI, F. S.; LUCENA, L. A crise da democracia brasileira. Uberlândia: Navegando publicações, 2017. p. 215-23. 
SILVA, Daniela Oliveira Vidal da; BRITO, Vera Lúcia Fernandes de; NUNES, Cláudio Pinto. Valorização docente na conjuntura do pós impeachement de 2016 no Brasil. Cocar, Belém, v. 13, n. 26, 2019. Disponível em:

<https://paginas.uepa.br/seer/index.php/cocar/article/view/2518>.Acesso em: $12 \mathrm{de}$ fevereiro de 2020.

SOUZA, Jamerson. Tendências Ideológicas do Conservadorismo. Tese (Doutorado em Serviço Social) - Programa de Pós-Graduação em Serviço Social, Universidade Federal de Pernambuco, 2016. Disponível em:

$<$ https://www.capes.gov.br/images/stories/download/pct/2017/Mencoes-

Honrosas/Servico-Social-Jamerson-Murillo-Anunciacao-de-Souza.PDF>. Acesso em: 14 abril 2020.

TEIXEIRA, Carlos Gustavo Poggio. O pensamento neoconservador em política externa nos Estados Unidos. Editora UNESP, 2010.

Recebido:09-05-2020

Aprovado: 12/07/2020 